\title{
Volume-based referral for cardiovascular procedures in the United States: a cross-sectional regression analysis Andrew J Epstein*1, Saif S Rathore ${ }^{2}$, Harlan M Krumholz ${ }^{1,2,3}$ and Kevin GM Volpp ${ }^{4,5}$
}

\begin{abstract}
Address: ${ }^{1}$ Division of Health Policy and Administration, Department of Epidemiology and Public Health, Yale University School of Medicine, New Haven, Connecticut, USA, ${ }^{2}$ Section of Cardiovascular Medicine, Department of Internal Medicine, Yale University School of Medicine, New Haven, Connecticut, USA, ${ }^{3}$ Yale-New Haven Hospital Center for Outcomes Research and Evaluation, New Haven, Connecticut, USA, ${ }^{4}$ Center for Health Equity Research and Promotion, Philadelphia Veterans' Affairs Hospital, Philadelphia, Pennsylvania, USA and ${ }^{5}$ Department of Health Care Systems, Wharton School of Business, and Section of General Internal Medicine, Department of Medicine, School of Medicine, both at University of Pennsylvania, Philadelphia, Pennsylvania, USA
\end{abstract}

Email: Andrew J Epstein* - andrew.epstein@yale.edu; Saif S Rathore - saif.rathore@yale.edu; Harlan M Krumholz - harlan.krumholz@yale.edu; Kevin GM Volpp - volpp70@mail.med.upenn.edu

* Corresponding author

Published: 03 June 2005

BMC Health Services Research 2005, 5:42 doi:10.1 186/1472-6963-5-42
Received: 24 January 2005

Accepted: 03 June 2005

This article is available from: http://www.biomedcentral.com/l472-6963/5/42

(C) 2005 Epstein et al; licensee BioMed Central Ltd.

This is an Open Access article distributed under the terms of the Creative Commons Attribution License (http://creativecommons.org/licenses/by/2.0), which permits unrestricted use, distribution, and reproduction in any medium, provided the original work is properly cited.

\begin{abstract}
Background: We sought to estimate the numbers of patients affected and deaths avoided by adopting the Leapfrog Group's recommended hospital procedure volume minimums for coronary artery bypass graft (CABG) surgery and percutaneous coronary intervention (PCl). In addition to hospital risk-adjusted mortality standards, the Leapfrog Group recommends annual hospital procedure minimums of 450 for $C A B G$ and 400 for $\mathrm{PCl}$ to reduce procedure-associated mortality.
\end{abstract}

Methods: We conducted a retrospective analysis of a national hospital discharge database to evaluate in-hospital mortality among patients who underwent $\mathrm{PCl}(\mathrm{n}=2,500,796)$ or CABG $(n=$ I,496,937) between 1998 and 200I. We calculated the number of patients treated at low volume hospitals and simulated the number of deaths potentially averted by moving all patients to high volume hospitals under best-case conditions (i.e., assuming the full volume-associated reduction in mortality and the capacity to move all patients to high volume hospitals with no related harms).

Results: Multivariate adjusted odds of in-hospital mortality were higher for patients treated in low volume hospitals compared with high volume hospitals for CABG (OR I.16, 95\% Cl I.10-1.24) and $\mathrm{PCl}(\mathrm{OR}$ I.12, 95\% Cl I.05-1.20). A policy of hospital volume minimums would have required moving 143,687 patients for $C A B G$ and 87,66 I patients for $\mathrm{PCl}$ from low volume to high volume hospitals annually and prevented an estimated 619 CABG deaths and $109 \mathrm{PCl}$ deaths. Thus, preventing a single death would have required moving $232 \mathrm{CABG}$ patients or $805 \mathrm{PCl}$ patients from low volume to high volume hospitals.

Conclusion: Recommended hospital CABG and PCl volume minimums would prevent 728 deaths annually in the United States, fewer than previously estimated. It is unclear whether a policy requiring the movement of large numbers of patients to avoid relatively few deaths is feasible or effective. 


\section{Background}

Patients treated at hospitals with higher volumes of cardiovascular procedures, including coronary artery bypass graft (CABG) surgery and percutaneous coronary intervention (PCI), are reported to have better outcomes than patients treated at hospitals with lower volumes [1-3]. These data have led to a growing interest in using volume to characterize hospital quality of care for cardiovascular procedures by purchaser and consumer organizations [4,5]. As part of its "Evidence-Based Hospital Referral" guidelines, the Leapfrog Group, a coalition of large health care purchasers that insure 34 million Americans, recommended until 2003 that its members contract for selected procedures, including CABG and PCI, only with hospitals that met minimum volume thresholds [6]. Hospital riskadjusted mortality criteria were added to the Leapfrog guidelines in 2003 [7].

Although proponents contend that implementing volume-based thresholds will reduce procedure-associated mortality, there are limited data on the number of patients affected by the adoption of volume minimums and the magnitude of any potential benefits. One study of patients hospitalized in California in 1997 suggested that 338 deaths might be prevented in that state each year by adopting volume minimums for CABG and PCI [8], and another study estimated that applying hospital volume minimums for CABG and PCI nationwide would save 1,871 lives annually [9]. However, both studies relied on estimates of hospital CABG [1] and PCI [3] volume-mortality associations using New York state data from the late 1980 s and early 1990 s. Recent research by Birkmeyer and Dimick [7] uses data from 2000 to estimate the volumemortality association and the national impact of the Leapfrog volume standards, and finds that 148,508 CABG cases would have to be moved to avert 594 deaths and 91,153 PCI cases would have to be moved to avert 547 deaths.

Because many purchasers have begun selective referral to providers that meet these Leapfrog criteria, it is important to understand the potential benefits and costs of the Leapfrog quality improvement recommendations. To provide an alternative, generalizable forecast of the potential consequences of adopting a volume-based referral policy, we conducted an evaluation of a hypothetical nationwide implementation of the Leapfrog Group's volume-based standards, the only criteria in effect until 2003, for CABG and PCI using nationally representative data from 19982001. We specifically sought to estimate the number of patients at low volume hospitals who would need to be moved to high volume hospitals and the number of deaths potentially averted by the adoption of hospital volume minimums.

\section{Methods \\ National Inpatient Sample}

Our analysis was based on the Nationwide Inpatient Sample (NIS), a hospital discharge database from the Agency for Healthcare Research and Quality's Health Care Utilization Project [10]. As the largest publicly available all-payer inpatient database in the United States, the NIS contains administrative records for all hospitalizations in a randomly selected national sample of non-governmental, acute care hospitals. The 2001 NIS, the most recent version of the NIS available at the time of our study, contains information on more than 7.4 million discharges from nearly 1,000 hospitals in 33 states, corresponding to nearly $20 \%$ of all admissions to US non-federal hospitals [11]. The NIS contains de-identified, hospitalization-level data, including information on primary and secondary diagnoses, demographic characteristics, procedure use, length of stay, payer, total charges, and admission and discharge status. Our study pooled data from the 1998, 1999, 2000, and 2001 NIS releases.

\section{Study sample}

We created separate, procedure-specific cohorts for hospitalizations in which a patient had any procedure code indicating a CABG (International Classification of Diseases, 9th Edition Clinical Modification [ICD-9-CM] codes 36.10-36.2) or PCI (ICD-9-CM codes 36.00-36.06 and 36.09). Of the nearly 29 million records in the 1998, 1999, 2000, and 2001 NIS, we identified 306,942 hospitalizations with a CABG and 517,178 hospitalizations with a PCI. We excluded patients under the age of 18 and neonatal or obstetric admissions in order to restrict our evaluation to a typical adult population. Hospitalizations with missing data for sex, age, or mortality were also excluded. To limit administrative data coding errors, we excluded patients treated at hospitals with fewer than 10 CABGs in any year from the CABG cohort and patients treated at hospitals with fewer than 5 PCIs in any year from the PCI cohort. Finally, following the Leapfrog Group's policy recommendation [12], we restricted our analysis to admissions at hospitals located in US Census Bureau-defined Metropolitan Statistical Areas, which are clusters of counties comprising large population centers. The two final unweighted procedure cohorts consisted of 296,135 hospitalizations for CABG drawn from 746 hospital-years of data and 496,252 hospitalizations for PCI drawn from 851 hospital-years of data. With the appropriate NIS sampling weights, these data represented 1,496,937 hospitalizations for CABG from 3,365 hospital-years and 2,500,796 hospitalizations for PCI from 4,141 hospital-years.

\section{Hospital volume groups}

To assess the association of hospital CABG and PCI volume and patient mortality, hospitals were divided into 
separate groups based on their annual volume. Hospitals were categorized as low volume if their annual volume was below the procedure-specific volume minimum recommended by the Leapfrog Group (450 cases for CABG, 400 cases for PCI) [7]. All other hospitals were considered to be high volume.

\section{Statistical analysis}

Patient characteristics, including demographics, admission type, comorbidities, and payer, were compared between patients treated in low volume hospitals and high volume hospitals within each procedure cohort using global chi-square analyses for categorical variables and simple t-tests for continuous variables.

The principal study outcome was in-hospital mortality. We compared crude rates of mortality between patients treated in high volume hospitals and low volume hospitals in each procedure cohort using global chi-square analysis. Unadjusted and multivariable logistic regressions that accounted for the NIS survey design were conducted within each procedure cohort to assess the association between treatment at a low volume hospital and patient mortality. Patient characteristics incorporated in the multivariable models, which were derived from previous administrative data-based evaluations of CABG and PCI and clinical judgment, included: sex, race (white, black, other), age (<65 years, 65-74 years, $\geq 75$ years), year, admission source, urgency of admission (emergent, urgent, elective, unknown/missing), coronary artery disease (principal diagnosis of MI [ICD-9-CM code 410], secondary diagnosis of $\mathrm{MI}$, any non-MI coronary disease diagnosis [ICD-9-CM codes 411-414], none), diabetes (ICD-9-CM code 250), chronic obstructive pulmonary disease (ICD-9-CM codes 490-496), hypertension (ICD9-CM codes 401-405), renal dysfunction (ICD-9-CM codes 580-586), congestive heart failure (ICD-9-CM codes 428, 402.01, 402.11, 402.91, 404.01, 404.11, 404.91), and peripheral vascular disease (ICD-9-CM codes 440,443$)$.

In addition to factors common to both procedure models, we added selected covariates to specific procedure volume analyses. The multivariable model for CABG mortality accounted for concomitant valve repair and other open heart surgery procedures (ICD-9-CM procedure code 35), use of an internal mammary graft (ICD-9-CM procedure codes 36.15, 36.16), and a same admission PCI (ICD-9CM procedure codes 36.00-36.06, 36.09). The analysis of hospital PCI volume controlled for multiple vessel PCI (ICD-9-CM procedure code 36.05).

\section{Estimating the effect of establishing hospital volume minimums}

To assess the impact of hospital volume minimum policy for CABG and PCI, we calculated the average annual number of patients treated at low volume hospitals in each procedure cohort. Observations were weighted using NIS sampling weights to obtain nationally generalizable estimates.

We then estimated the number of deaths that could be prevented by the universal adoption of hospital volume minimums using mortality estimates obtained from the procedure-specific multivariable logistic regression models. Volume at low volume hospitals was modeled using a logarithmic transformation based on previous studies suggesting hospital volume-mortality associations exhibit a log-linear relationship [13-15]. Volume at high volume hospitals was modeled with a single dummy variable to reflect the average volume-associated mortality effect in high volume hospitals. An initial risk-adjusted probability of mortality was calculated for each hospitalization using the current distribution of patients across hospital volume groups. To derive a "best case" estimate of the impact of a hospital volume minimum policy, we assumed that all patients at low volume hospitals could be transported to high volume hospitals. A second risk-adjusted probability of mortality was then calculated for hospitalizations treated in low volume hospitals assuming that they had been treated in a typical high volume hospital by setting the hospital volume effect for low volume hospital patients to the average hospital volume effect for patients treated in high volume hospitals. This process removed any measured volume-associated difference in mortality between patients treated in low volume and high volume hospitals. Differences in weighted risk-adjusted probabilities between the two scenarios were summed across all low volume hospital patients to determine the estimated number of deaths averted by the adoption of hospital volume minimums for CABG and PCI.

Statistical analyses were conducted using SAS 8.2 (SAS Institute, Cary, NC) and Stata 8.2 (Stata Corporation, College Station, TX). Analysis of the NIS database was approved by the University of Pennsylvania Institutional Review Board.

\section{Results}

\section{Patient characteristics}

The proportion of patients treated at low volume hospitals was $14.0 \%$ for PCI and $38.4 \%$ for CABG. Mean patient age was 64.2 for PCI and 66.0 for CABG, and was generally comparable for patients treated in low volume and high volume hospitals. A greater proportion of patients treated at low volume CABG and PCI hospitals were non-white, while a lower proportion represented 
Table I: Patient characteristics across hospital volume groups

\begin{tabular}{|c|c|c|c|c|c|c|c|c|}
\hline \multirow[t]{2}{*}{ Characteristics } & \multicolumn{3}{|c|}{ Hospital CABG Volume } & \multicolumn{5}{|c|}{ Hospital PCI Volume } \\
\hline & Overall & Low $(<450)$ & High $(\geq 450)$ & $\mathbf{P}$ & Overall & Low $(<400)$ & High $(\geq 400)$ & $\mathbf{P}$ \\
\hline$\%$ of patients (weighted) & 100.0 & 38.4 & 61.6 & - & 100.0 & 14.0 & 86.0 & - \\
\hline$\%$ of hospital year groups* & 100.0 & 69.8 & 30.2 & - & 100.0 & 45.1 & 54.9 & - \\
\hline Mean age, $(\mathrm{SD})$ years & $66.0(0.07)$ & $65.9(0.08)$ & $66.1(0.11)$ & 0.12 & $64.2(0.08)$ & $63.7(0.12)$ & $64.2(0.09)$ & $<0.001$ \\
\hline Age & & & & 0.11 & & & & $<0.001$ \\
\hline Less than 65 & 41.1 & 41.7 & 40.7 & & 48.7 & 50.7 & 48.3 & \\
\hline $65-74$ years & 34.5 & 34.2 & 34.7 & & 28.8 & 27.6 & 29.0 & \\
\hline 75 years of age and older & 24.4 & 24.1 & 24.6 & & 22.5 & 21.7 & 22.6 & \\
\hline Male & 69.5 & 69.4 & 69.5 & 0.90 & 65.5 & 64.4 & 65.7 & $<0.001$ \\
\hline Race & & & & 0.014 & & & & 0.016 \\
\hline White & 64.2 & 59.2 & 67.3 & & 63.3 & 56.7 & 64.4 & \\
\hline Black & 3.8 & 3.8 & 3.9 & & 4.5 & 5.1 & 4.4 & \\
\hline Other & 7.5 & 9.5 & 6.2 & & 7.3 & 10.1 & 6.9 & \\
\hline Race not reported/missing & 24.5 & 27.6 & 22.6 & & 24.9 & 28.1 & 24.4 & \\
\hline Primary payer & & & & $<0.001$ & & & & $<0.001$ \\
\hline Medicare & 53.8 & 51.9 & 55.0 & & 49.0 & 45.7 & 49.5 & \\
\hline Medicaid & 4.0 & 4.7 & 3.5 & & 4.0 & 5.3 & 3.8 & \\
\hline Private & 37.3 & 37.4 & 37.3 & & 41.2 & 40.6 & 41.4 & \\
\hline Other/missing & 4.9 & 6.0 & 4.2 & & 5.8 & 8.4 & 5.4 & \\
\hline Diabetes & 29.5 & 29.8 & 29.3 & 0.14 & 24.9 & 25.4 & 24.8 & 0.12 \\
\hline Hypertension & 58.6 & 58.0 & 58.9 & 0.098 & 54.1 & 53.0 & 54.3 & 0.022 \\
\hline COPD & 17.3 & 17.5 & 17.2 & 0.37 & 11.2 & 11.9 & 11.0 & 0.002 \\
\hline Congestive heart failure & 17.6 & 17.5 & 17.7 & 0.64 & 9.9 & 10.7 & 9.8 & $<0.001$ \\
\hline Peripheral vascular disease & 7.6 & 7.5 & 7.6 & 0.55 & 5.6 & 5.4 & 5.6 & 0.43 \\
\hline Renal disease & 6.0 & 5.8 & 6.1 & 0.11 & 2.6 & 2.9 & 2.5 & $<0.001$ \\
\hline Coronary disease & & & & $<0.001$ & & & & $<0.001$ \\
\hline $\mathrm{Ml}$ as primary diagnosis & 20.3 & 20.1 & 20.4 & & 31.0 & 37.6 & 29.9 & \\
\hline $\mathrm{Ml}$ as secondary diagnosis & 5.7 & 6.3 & 5.3 & & 4.5 & 5.0 & 4.4 & \\
\hline Other coronary artery disease & 65.6 & 65.5 & 65.7 & & 60.2 & 53.1 & 61.4 & \\
\hline No coronary disease & 8.4 & 8.1 & 8.6 & & 4.3 & 4.3 & 4.3 & \\
\hline Admission type & & & & $<0.001$ & & & & $<0.001$ \\
\hline Emergency & 23.7 & 23.8 & 23.6 & & 31.9 & 36.9 & 31.1 & \\
\hline Urgent & 25.2 & 22.1 & 27.1 & & 26.1 & 23.6 & 26.5 & \\
\hline Elective & 41.5 & 38.6 & 43.4 & & 32.3 & 21.5 & 34.1 & \\
\hline Other/missing & 9.6 & 15.6 & 5.9 & & 9.6 & 18.1 & 8.2 & \\
\hline Arrived by inter-hospital transfer & & & & $<0.001$ & & & & $<0.001$ \\
\hline Yes & 18.0 & 11.5 & 22.0 & & 18.2 & 9.0 & 19.7 & \\
\hline No & 78.8 & 85.4 & 74.7 & & 78.4 & 88.4 & 76.8 & \\
\hline Unknown & 3.2 & 3.2 & 3.3 & & 3.4 & 2.7 & 3.6 & \\
\hline Year & & & & 0.59 & & & & 0.17 \\
\hline 1998 & 25.4 & 26.0 & 25.1 & & 22.0 & 25.6 & 21.4 & \\
\hline 1999 & 23.7 & 21.5 & 25.1 & & 22.2 & 24.2 & 21.9 & \\
\hline 2000 & 25.5 & 25.2 & 25.7 & & 26.0 & 25.6 & 26.1 & \\
\hline 2001 & 25.3 & 27.4 & 24.0 & & 29.8 & 24.6 & 30.6 & \\
\hline \multicolumn{9}{|l|}{ Procedure-specific variables } \\
\hline Same admission $\mathrm{PCl}$ & 2.8 & 3.3 & 2.4 & $<0.001$ & - & - & - & - \\
\hline Concomitant valve procedure & 10.6 & 9.5 & 11.3 & $<0.001$ & - & - & - & - \\
\hline Internal mammary artery graft & 16.8 & 13.4 & 18.8 & $<0.001$ & - & - & - & - \\
\hline Multivessel $\mathrm{PCl}$ & - & - & - & - & 14.5 & 14.8 & 12.6 & $<0.001$ \\
\hline
\end{tabular}

Unless noted otherwise, findings are expressed as percentages

Percentages may not sum to 100 due to rounding

* Hospital year groups refer to the number of hospitals that contributed data in each year of the NIS. A hospital participating in the NIS over the 3 year period would be considered to have contributed 3 hospital year groups to the analysis. 
Table 2: Patient mortality by hospital volume groups

\begin{tabular}{|c|c|c|c|c|}
\hline & Hospital CABG Volume & & & \\
\hline & Overall & Low $(<450)$ & High ( $\geq 450)$ & $\mathbf{P}$ \\
\hline Crude rates & 3.6 & 3.9 & 3.5 & 0.002 \\
\hline $\begin{array}{l}\text { Unadjusted odds ratio } \\
(95 \% \mathrm{Cl})\end{array}$ & - & $1.10(1.04-1.16)$ & 1.00 [referent] & 0.001 \\
\hline \multirow{3}{*}{$\begin{array}{l}\text { Adjusted odds ratio (95\% } \\
\mathrm{Cl})\end{array}$} & - & $1.16(1.10-1.24)$ & 1.00 [referent] & $<0.001$ \\
\hline & Hospital PCI Volume & & & \\
\hline & Overall & Low $(<400)$ & High $(\geq 400)$ & $\mathbf{P}$ \\
\hline Crude rates & 1.5 & 2.0 & 1.43 & $<0.001$ \\
\hline $\begin{array}{l}\text { Unadjusted odds ratio } \\
(95 \% \mathrm{Cl})\end{array}$ & - & $1.37(1.28-1.49)$ & 1.00 [referent] & $<0.001$ \\
\hline $\begin{array}{l}\text { Adjusted odds ratio }(95 \% \\
\mathrm{Cl})\end{array}$ & - & $1.12(1.05-1.20)$ & 1.00 [referent] & 0.001 \\
\hline
\end{tabular}

elective admissions or patients received in transfer as compared with patients treated at high volume hospitals for both procedures. The proportion of CABG patients receiving internal mammary artery grafts was slightly greater in high volume hospitals while the proportion of PCI patients with a myocardial infarction was slightly higher in low volume hospitals. Other patient characteristics, including sex distribution and prevalence of comorbid conditions, were generally comparable between patients at low volume and high volume hospitals (Table 1).

\section{Hospital procedure volume and mortality}

Crude in-hospital mortality was $3.64 \%$ for patients undergoing CABG and $1.50 \%$ for patients undergoing PCI. Inhospital mortality rates were higher for patients treated in low volume hospitals compared with high volume hospitals for CABG $(3.85 \%$ vs. $3.51 \%, \mathrm{P}=0.002)$ and $\mathrm{PCI}$ $(1.96 \%$ vs. $1.43 \%, \mathrm{P}<0.001)$. Patients at low volume hospitals remained at increased risk of in-hospital mortality after multivariable adjustment for CABG (odds ratio [OR] $1.16,95 \%$ confidence interval [CI] 1.10-1.24) and PCI (OR 1.12, 95\% CI 1.05-1.20) compared with patients at high volume hospitals (Table 2).

\section{Impact of hospital procedure volume minimums}

Implementation of a hospital procedure volume minimum policy for cardiovascular procedures would require the transfer of an estimated 231,348 total patients each year, 143,687 patients for CABG, and 87,661 for PCI. A best-case estimate suggests the transfer of patients from low volume to high volume hospitals annually could have prevented 728 in-hospital deaths. The majority of annual deaths prevented by the transfer of patients to high volume hospitals were for patients undergoing CABG (619 deaths, $4.5 \%$ of all CABG deaths), with 109 deaths $(1.2 \%$ of all PCI deaths) avoided among patients undergoing
PCI. Adoption of a hospital volume minimum policy would thus require the transfer of 232 patients from low volume to high volume CABG hospitals to avert a single death, and 805 patients from low volume to high volume PCI hospitals to avert a single death (Table 3 ).

\section{Discussion}

The nationwide implementation of a hospital volume minimum policy for cardiovascular procedures based on volume thresholds promoted by the Leapfrog Group [7] would have required the annual redistribution of more than 231,000 patients who underwent CABG or PCI at low volume hospitals between 1998 and 2001. At best, this redistribution would have resulted in approximately 728 fewer deaths annually, concentrated primarily among patients who underwent CABG (619 deaths). This suggests that previously reported mortality benefits associated with volume minimums for PCI may be overstated (547 deaths averted vs. 109) [7]. Differences between our estimates and previous ones are driven more by methodology than data. Whereas previous studies assumed that all patients moved from low- to high-volume centers would receive the same average mortality benefit, our methodology calculated the expected benefit for each patient at a low-volume center based on the volume of the center and the patient's comorbidities.

The potential to avert up to 728 deaths each year through the treatment of CABG and PCI patients at only high volume hospitals may be interpreted as sufficient evidence for the adoption of a procedure volume minimum policy. However, this benefit must also be considered in the context of the required transfer of over 231,000 patients each year from low volume to high volume hospitals. Because the average absolute incremental increase in mortality associated with treatment at a low volume hospital com- 
Table 3: Volume and mortality estimates

\begin{tabular}{|c|c|c|}
\hline & CABG & PCI \\
\hline \multicolumn{3}{|l|}{ Current } \\
\hline Total procedures, $n(\%)$ & 374,234 & 625,199 \\
\hline Performed at LVH, n(\%) & 143,687 & 87,661 \\
\hline Performed at HVH, $n(\%)$ & 230,547 & 537,538 \\
\hline Total in-hospital deaths, $\mathrm{n}(\%)$ & 13,633 & 9,405 \\
\hline Performed at LVH, n(\%) & 5,535 & 1,719 \\
\hline Performed at HVH, n(\%) & 8,098 & 7,686 \\
\hline \multicolumn{3}{|l|}{ Adopting volume minimum policy } \\
\hline Total procedures, $\mathrm{n}(\%)$ & 374,234 & 625,199 \\
\hline Performed at LVH, n(\%) & 0 & 0 \\
\hline Performed at HVH, n(\%) & 374,234 & 625,199 \\
\hline Total in-hospital deaths, $\mathrm{n}(\%)$ & 13,014 & 9,296 \\
\hline Performed at LVH, n(\%) & 0 & 0 \\
\hline Performed at HVH, n(\%) & 13,014 & 9,296 \\
\hline \multicolumn{3}{|l|}{ Impact of adopting volume minimum policy } \\
\hline Procedures moved from $\mathrm{LVH}$ to $\mathrm{HVH}, \mathrm{n}$ & 143,687 & 87,661 \\
\hline Deaths averted, $\mathrm{n}$ & 619 & 109 \\
\hline Number of procedures moved from LVH to $\mathrm{HVH}$ to avoid I death & 232 & 805 \\
\hline Percent reduction in deaths & $4.54 \%$ & $1.16 \%$ \\
\hline
\end{tabular}

pared with a high volume hospital is generally small $(<0.5 \%)$, particularly for patients undergoing PCI, a large number of patients would need to be treated at high volume hospitals ( 805 for PCI) in order to avert a single death. This number needed to treat is larger than that of most current cardiovascular drugs and therapies, suggesting only a modest benefit for any individual patient [16]. Moreover, the number of deaths attributable to treatment at low versus high volume hospitals represents only a small proportion of overall procedure mortality ( $4.5 \%$ of CABG deaths, $1.2 \%$ of PCI deaths). Recent studies also suggest substantial heterogeneity in CABG and PCI outcomes among hospitals, including low volume hospitals with better than predicted outcomes and high volume hospitals with worse than predicted outcomes $[17,18]$. As such, hospital volume may be both a modest and unreliable measure of any individual hospital's performance [19].

Policies regulating hospital procedure volume minimums may also have potential adverse consequences. Concentrating services among fewer providers may adversely affect access to procedures in many areas of the country [20]. Differences in patient characteristics between low and high volume hospitals in our analysis suggest the sus- pension of services at low volume hospitals may disproportionately affect minorities and patients with Medicaid insurance, groups with historically limited access to cardiovascular care. A reduction in the number of CABG and PCI providers may also result in higher prices for health care purchasers as provider competition is reduced. Adoption of volume thresholds may unwittingly motivate providers to treat patients with borderline indications in order to meet volume minimums. Patients may not support regionalization of procedures associated with hospital volume minimums if they prefer receiving care at local, low volume hospitals [21]. Each of these and other factors requires consideration prior to adopting any hospital volume minimum policy.

\section{Limitations}

Although our analysis provides estimates of the mortality reductions that may be achieved through hospital volume minimums, we necessarily make several assumptions. First, we assumed that high volume hospitals achieved superior outcomes because of their higher volumes [22]. If high volume hospitals have better outcomes because of patient selection or factors other than hospital volume itself, the mortality benefit and number of lives saved reported by transferring patients from low volume hospi- 
tals may be overstated. Second, our analysis assumes that all patients can be shifted from low volume hospitals to high volume hospitals and accrue a hospital volume-associated mortality benefit. No study to date has tested this assertion, and its validity remains unknown [23]. Third, because it is impossible to know the exact volume of the high volume hospital to which a low volume hospital patient would be transferred, we assumed that all low volume hospital patients would receive the average benefit of being treated at a high volume hospital. Finally, our analysis assumes that redistributing patients across hospitals has no adverse consequences.

Our study has a number of limitations. First, the NIS database is based on administrative data, and may be susceptible to hospital-based variations in coding practices. Previous studies, however, have demonstrated that administrative databases contain sufficient information to evaluate hospital differences in procedure quality [24], and the NIS is a comprehensive, nationally representative, all-payer database that includes information on cardiovascular procedure use. Second, we evaluated in-hospital mortality and were unable to assess other outcomes, including procedural complications or post-discharge events. However, the Leapfrog Group's volume recommendations are predicated on a mortality reduction, not improvement on other outcomes [6,7]. Third, the NIS does not collect data concerning physician volume, and thus we could not assess the effect of operator volume. However, previous studies suggest hospital volume is associated with outcomes even after accounting for operator volume $[13,25,26]$. Learning by doing and/or (dis)economies of scale, which are not captured in this analysis, may also influence estimates of the impact of a hospital volume minimum policy. Finally, the NIS does not contain unique patient identifiers, and the possible inclusion of multiple patient admissions in our cohort may violate statistical assumptions of independence.

\section{Conclusion}

Implementation of a hospital volume minimum policy for CABG and PCI based on the Leapfrog Group's Evidence Based Hospital Referral guidelines in effect until 2003 would have required the annual redistribution of over 231,000 patients from low volume hospitals to high volume hospitals between 1998 and 2001. This policy would have resulted in, at best, an estimated 728 fewer deaths annually, primarily among patients undergoing CABG. These estimates rely on the unproven assumption that simply directing all patients to high volume hospitals would eliminate the full differential in mortality between low and high volume hospitals. Further, given the uncertain feasibility and potential adverse consequences, requiring the movement of 232 patients for CABG or 805 patients for PCI between hospitals to avert a single death may not be an effective policy. These issues deserve further study before hospital procedure volume minimum policies for CABG and PCI are adopted more widely by purchasers.

\section{Competing interests}

The authors declare that they have no competing interests.

\section{Authors' contributions}

AJE and SSR were the principal authors of the manuscript. AJE was the principal data analyst. AJE, SSR, HMK and KGMV participated in study conception, interpretation, and drafting of the manuscript. AJE and KGMV were involved with data acquisition. All authors read and approved the final manuscript.

\section{Acknowledgements}

At the time this research was conducted, AJE was supported by a National Research Service Award (T32-HS00009) from the Agency for Healthcare Research and Quality at the University of Pennsylvania. SSR was supported by a Medical Scientist Training Grant (GM07205) from the National Institutes of Health National Institute of General Medical Sciences. KGMV was supported by a Veterans' Affairs Health Services Research and Development Career Development Award and a Doris Duke Foundation Clinical Scientist Development Grant.

\section{References}

I. Hannan EL, Kilburn HJ, Bernard H, O'Donnell JF, Lukacik G, Shields EP: Coronary artery bypass surgery: the relationship between inhospital mortality rate and surgical volume after controlling for clinical risk factors. Med Care |99|, 29:1094-1107.

2. Hannan EL, Popp AJ, Tranmer B, Fuestel P, Waldman J, Shah D: Relationship between provider volume and mortality for carotid endarterectomies in New York state. Stroke 1998, 29:2292-2297.

3. Hannan EL, Racz M, Ryan TJ, McCallister BD, Johnson LW, Arani DT, Guerci AD, Sosa J, Topol EJ: Coronary angioplasty volume-outcome relationships for hospitals and cardiologists. JAMA 1997, 277:892-898.

4. Anonymous: Hospital ratings. [http://www.healthscope.org]

5. Center for Medical Consumers: Center for Medical Consumers. [http://www.medicalconsumers.org].

6. The Leapfrog Group: Evidence-based hospital referral. [http:// www.leapfroggroup.org/media/file/Leapfrog-Evidencebased Hospital Referral Fact Sheet.pdf].

7. Birkmeyer JD, Dimick JB: Potential benefits of the new Leapfrog standards: effect of process and outcomes measures. Surgery 2004, I35:569-575.

8. Dudley RA, Johansen KL, Brand R, Rennie DJ, Milstein A: Selective referral to high-volume hospitals: estimating potentially avoidable deaths. JAMA 2000, 283:1159-1166.

9. Birkmeyer JD, Finlayson EVA, Birkmeyer CM: Volume standards for high-risk surgical procedures: potential benefits of the Leapfrog initiative. Surgery 200I, 130:415-422.

10. Steiner C, Elixhauser A, Schnaier J: The Healthcare Cost and Utilization Project: an overview. Eff Clin Pract 2002, 5: |43-15।.

II. Anonymous: National Inpatient Sample. [http://www.hcupus.ahrq.gov/nisoverview.jsp].

12. Birkmeyer JD, Birkmeyer CM, Wennberg DE, Young M: Leapfrog patient safety standards: the potential benefits of universal adoption. 2004 [http://www.leapfroggroup.org/media/file/LeapfrogBirkmeyer.pdf]. Leapfrog Group

13. Birkmeyer JD, Stukel TA, Siewers AE, Goodney PP, Wennberg DE, Lucas FL: Surgeon volume and operative mortality in the United States. N Engl J Med 2003, 349:2 I I 7-2 I 27. 
14. Jollis JG, Peterson ED, DeLong ER, Mark DB, Collins SR, Muhlbaier $\mathrm{LH}$, Pryor DB: The relation between the volume of coronary angioplasty procedures at hospitals treating Medicare beneficiaries and short-term mortality. N Engl J Med 1994, 33I:1625-1629.

15. Jollis JG, Peterson ED, Nelson CL, Stafford JA, DeLong ER, Muhlbaier LH, Mark DB: Relationship between physician and hospital coronary angioplasty volume and outcome in elderly patients. Circulation 1997, 95:2485-2491.

16. Anonymous: Number Needed to Treat (NNT). [http:// www.cebm.utoronto.ca/glossary/nntsPrint.htm].

17. Rathore SS, Epstein AJ, Volpp KGM, Krumholz HM: Hospital coronary artery bypass graft surgery volume and patient mortality, 1998-2000. Ann Surg 2004, 239: I I0-1 I7.

18. Epstein AJ, Rathore SS, Volpp KGM, Krumholz HM: Hospital percuatenous coronary intervention volume and patient mortality, 1998 to 2000: does the evidence support current procedure volume minimums? J Am Coll Cardiol 2004, 43:1755-1762.

19. Peterson ED, Coombs LP, DeLong ER, Haan CK, Ferguson TB: Procedural volume as a marker of quality for CABG surgery. JAMA 2004, 29 I: I95-201.

20. Petersen LA, Normand SL, Leape LL, McNeil B]: Regionalization and the underuse of angiography in the Veterans Affairs health care system as compared with a fee-for-service system. N Engl J Med 2003, 348:2209-22I7.

21. Finlayson SRG, Birkmeyer CM, Tosteson ANA, Nease RFJ: Patient preferences for location of care: implications for regionalization. Med Care 1999, 37:204-209.

22. Shahian DM, Normand SLT: The volume-outcome relationship: from Luft to Leapfrog. Ann Thorac Surg 2003, 75: 1048-1058.

23. Epstein AJ, Rathore SS: Coronary artery bypass surgery, hospital volume, and risk. Circulation 2003, 108:e6-e7.

24. Jones RH, Hannan EL, Hammermeister KE, DeLong ER, O'Connor GT, Luepker RV, Parsonnet V, Pryor DB, for the Working Group Panel on the Cooperative CABG Database Project: Identification of preoperative variables needed for risk-adjustment of short-term mortality after coronary artery bypass graft surgery. J Am Coll Cardiol 1996, 28: I478-I487.

25. Hannan EL, Wu C, Ryan TJ, Bennett E, Culliford AT, Gold JP, Hartman A, Isom OW, Jones RH, McNeil B, Rose EA, Subramanian VA: Do hospitals and surgeons with higher coronary artery bypass graft surgery volumes still have lower risk-adjusted mortality rates? Circulation 2003, 108:795-80I.

26. McGrath PD, Wennberg DE, Dickens JDJ, Siewers AE, Lucas FL, Malenka DJ, Kellett MAJ, Ryan TJJ: Relation between operator and hospital volume and outcomes following percutaneous coronary interventions in the era of the coronary stent. JAMA 2000, 284:3|39-3| 44

\section{Pre-publication history}

The pre-publication history for this paper can be accessed here:

http://www.biomedcentral.com/1472-6963/5/42/prepub

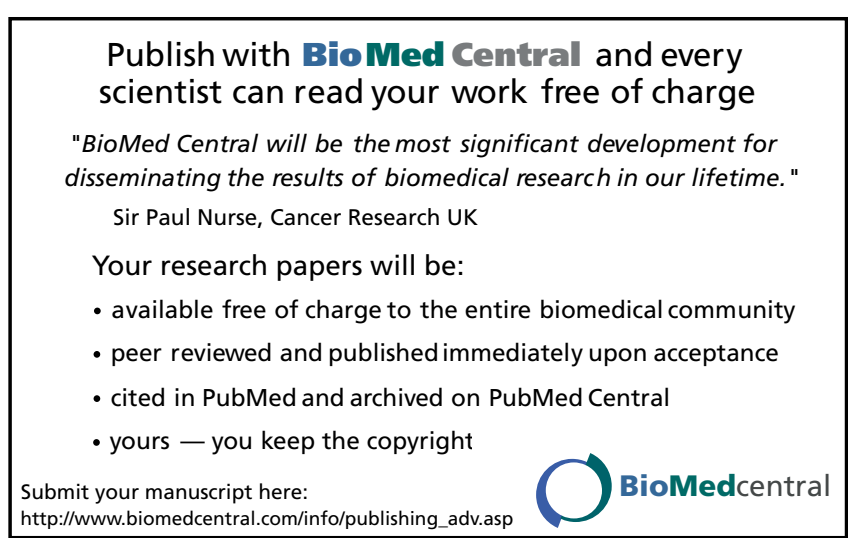

